\title{
Formação Continuada de Educadores/As: Uma Experiência a Partir da Práxis das/nas Escolas do Campo no Município de São Mateus-ES
}

Continuing Education Of Educators: An Experience From The Praxis Of/In The Schools Of The Countryside In The Municipality Of São Mateus-ES

\author{
Ozana Luzia Galvão Baldotto \\ Adelar João Pizetta \\ Vitor Eduardo Mendes de Oliveira \\ Renata Cristina Araújo Gomes \\ Fernando Vittorazzi Braz \\ Eliete Rosa Fernandes
}

\begin{abstract}
Resumo: Neste artigo relatamos a experiência da Formação Continuada de Educadores/as: uma experiência a partir da práxis das/nas Escolas do Campo no Município de São Mateus - ES, realizada no ano de 2019, com professores, pedagogos e diretores que atuavam em escolas campesinas na ocasião, com vistas a compreender, de que maneira a formação continuada pode contribuir para a melhoria do processo de ensino-aprendizagem. Considerando as Legislações brasileiras e mateenses que delineiam essa modalidade de ensino, buscamos compreender como se apresenta a Proposta de Educação do Campo do Município de São Mateus, de que maneira ela pode ser verificada na prática pedagógica por meio dos instrumentos propostos e quais as intervenções necessárias para a melhoria/qualificação desse processo. Pudemos compreender que a práxis pedagógica dessa modalidade vem avançando e para que essa melhoria continue crescente é de fato a formação continuada com foco nos objetivos da escola, uma ferramenta imprescindível. A parceria estabelecida junto à UFES, por intermédio de um projeto de extensão, proporcionou um envolvimento entre Educação Básica e Universidade, o que contribuiu para o diálogo e fortalecimento do "fazer pedagógico" de ambas as partes.
\end{abstract}

Palavras-Chave: Educação do Campo. Formação Continuada. Práxis.

Abstract: In this article we report the experience of continuing education of educators: an experience from the praxis of/in the Field Schools in the municipality of São Mateus ES, carried out in 2019 with teachers, pedagogues and principals who worked in peasant schools at the time, with a view to understanding how continuing education can contribute to the improvement of the teaching-learning process. Considering the Brazilian and mateense laws that outline this modality of teaching, we seek to understand how the Field Education Proposal of the municipality of São Mateus is presented, how it can be verified in pedagogical practice through the proposed instruments and what interventions are necessary for the improvement/qualification of this process. We could understand that the pedagogical proposals for this modality have been advancing in our municipality and for this improvement to continue increasing is in fact the continued education focused on the objectives of the school, an indispensable tool. The partnership established with UFES provided an involvement between Basic Education and the University, which contributes to the dialogue and strengthening of the "pedagogical practice" of both parties.

Keywords: Field Education. Continuing Education. Praxis. 


\section{Introdução}

O texto que segue trata da sistematização e relato de experiência sobre o Projeto de Extensão intitulado "Formação Continuada de Educadores/as: Dimensões Pedagógicas das Práticas Educativas nas Escolas do Campo no Município de São Mateus/ES”, que aconteceu no decorrer do ano de 2019, com a coordenação do Professor Adelar João Pizetta, vinculado ao Centro De Educação e Ciências Humanas (DECH/CEUNES/UFES), em parceria com a Secretaria Municipal de Educação de São Mateus/ES, por meio do Setor de Educação do Campo.

Dessa maneira, este artigo tem como objetivo relatar a experiência da Formação Continuada de Educadores/as, com vistas a compreender o papel da formação continuada na melhoria do processo de ensino-aprendizagem das escolas campesinas e no fortalecimento do Projeto Político Pedagógico junto aos estudantes, comunidades, educadores e Secretaria Municipal de Educação de São Mateus.

Para tanto, é necessário compreender o processo histórico que delineia essa modalidade de ensino, com o devido destaque para a memória nacional e para a trajetória de construção percorrida no Município de São Mateus.

Nesse contexto, foi indispensável abordar as legislações municipais estruturadas para amparo da modalidade e, principalmente, o movimento de construção do Projeto Político Pedagógico da Educação do Campo no âmbito municipal, evidenciando a participação dos sujeitos do campo.

\section{Alguns Elementos Históricos da Construção da Educação do Campo}

No final do século XX e início do século XXI, o debate sobre a educação rural ganhou destaque no cenário nacional em decorrência dos movimentos sociais do campo. Ganham destaque: I ENERA - Encontro Nacional das Educadoras e dos Educadores da Reforma Agrária, em 1997, promovido pelo MST, UNB, UNESCO, UNICEF e CNBB, seguido pela primeira Conferência Por Uma Educação Básica do Campo, realizada em Luziânia-GO, em 1998.

Essa conferência representou a consagração coletiva de um novo jeito de lutar e de pensar a educação para o povo brasileiro que trabalha e que vive NO 
e DO campo (ARROYO; CALDART; MOLINA, 2011). Dessa forma foi inaugurada uma nova referência para o debate da Educação do Campo e não da educação rural ou a educação para o meio rural.

Em 2004, aconteceu a II Conferência Nacional de Educação do Campo com o seu tema alterado de "Por Uma Educação Básica do Campo" para "Por Uma Educação do Campo" (PIRES, 2012, p. 97), onde se incluía a necessidade pelo direito de acesso ao ensino superior.

No ano de 2015, ocorre o II ENERA - Encontro Nacional das Educadoras e dos Educadores da Reforma Agrária, na cidade de Luziânia - GO, com a participação de aproximadamente 1500 educadores. Nesse encontro foi socializado o "Manifesto das Educadoras e dos Educadores da Reforma Agrária", que destaca diversos pontos da realidade atual, dentre os quais, separamos dois para este artigo:

[...] 6. Grandes grupos empresariais intervêm cada vez mais na política educacional, por meio de propostas que têm sido assumidas pelos governos com o falso objetivo de melhorar a qualidade das escolas públicas. Na prática, representam um processo acelerado de mercantilização da educação em todos os níveis. Primeiro, buscam demonstrar que a escola pública está em crise, que os educandos e educandas não aprendem, os professores e professoras não sabem ensinar e o sistema educacional não funciona. Depois, apresentam como alternativa que as escolas passem a funcionar de acordo com a lógica de trabalho e de gestão das empresas capitalistas. Isso significa o estabelecimento de metas a serem atingidas, controle externo do processo pedagógico, perda de autonomia do trabalho dos educadores e educadoras, responsabilização individual pela aprendizagem dos educandos e educandas sob qualquer condição e currículos determinados em função da avaliação em larga escala. Defendem, que para maior eficiência do modelo, as próprias empresas assumam a gestão das escolas, recebendo recursos públicos para esta tarefa. Esses grandes grupos empresariais se organizam no "Movimento Todos pela Educação".

[...] 9. No Brasil, o direito à educação dos trabalhadores e trabalhadoras ainda não foi resolvido. O projeto escravocrata, latifundista e agroexportador do país, explica porque sequer chegamos à universalização da educação básica e porque existem 14 milhões de jovens e adultos ainda não alfabetizados. Este projeto é responsável pela desigualdade histórica de direitos dos trabalhadores e das trabalhadoras do campo. (II ENCONTRO NACIONAL DAS EDUCADORAS E DOS EDUCADORES DA REFORMA AGRÁRIA. Manifesto das 
Educadoras e dos educadores da Reforma Agrária. Luziânia GO, 21 a 25 de setembro de 2015).

Dessa forma, torna-se impossível a construção de um projeto de Educação do Campo sem o envolvimento dos sujeitos que vivem no campo. Aceitar algo desse tipo seria retroceder no movimento de construção da modalidade e negar todas as experiências de Educação do Campo que existem no país, e nesse contexto, Caldart (2011, p. 151) destaca que:

[...] nosso movimento por uma educação do campo se afirma como um basta aos 'pacotes' e à tentativa de fazer das pessoas que vivem no campo instrumentos de implementação de modelos que as ignoram ou escravizam. Basta também de visão estreita de educação como preparação de mão de obra e a serviço do mercado. Queremos participar diretamente da construção do nosso projeto educativo; queremos aprender a pensar sobre educação que nos interessa enquanto seres humanos, enquanto sujeitos de diferentes culturas, enquanto classe trabalhadora do campo, enquanto sujeitos das transformações necessárias ao nosso país, enquanto cidadãos do mundo.

Na trajetória deste movimento educativo, algumas práticas pedagógicas foram socializadas como iniciativas da própria população, por intermédio de suas organizações e de seus movimentos sociais, no sentido de reagir ao processo de exclusão e forçar políticas públicas que garantam o acesso à educação e a construção da identidade das escolas do campo. São exemplos destacados:

as Escolas-Família Agrícola (EFAs), que existem em vários estados há 30 anos, com mais de duzentos centros educativos em alternância espalhados pelo Brasil, voltados para a educação dos filhos/filhas da agricultura familiar; [...]

as várias iniciativas no campo da alfabetização de jovens e de adultos, como por exemplo o trabalho do Movimento da Educação de Base (MEB);

a luta do MST pelas escolas de assentamento e de acampamento e suas experiências na área de formação de professores e de técnicos da área de produção;

a preocupação do Movimento dos atingidos por Barragens (MAB) com as escolas de reassentamentos;

a luta dos indígenas e dos povos da floresta por uma escola vinculada à sua cultura; $e$ 
as diversas iniciativas tomadas pelas comunidades e pelos professores/professoras de inúmeras escolas isoladas, espalhadas nos vários cantos do país, que lutam pela sobrevivência e pela dignidade de seu trabalho (KOLLING; NERY; MOLINA, 1999 [?], p. 46-47).

Nesse contexto de articulação e socialização das práticas já existentes nas comunidades camponesas, é importante destacar as experiências de Educação existentes nessas comunidades do Estado do Espírito Santo, a partir da década de 1970, como: as Escolas Famílias Agrícolas - EFA's ${ }^{1}$, as Escolas de Assentamentos, as Escolas Multisseriadas (Escolas Unidocentes e Pluridocentes) e as Escolas Comunitárias Rurais.

\section{Histórico do movimento da Educação do Campo no Município de São Mateus}

Em 1972, acontece a implantação da Escola Família Agrícola (EFA) de Nestor Gomes - km 41, Município de São Mateus, por meio do Movimento de Educação Promocional do Espírito Santo (MEPES)².

Rocha (2007) enfatiza que a Pedagogia da Alternância tem o objetivo de romper com um sistema de educação fechado, elitizado e distanciado da realidade dos estudantes:

Dessa forma, a Pedagogia da alternância propõe uma Formação Integral que leve em conta todas as dimensões da pessoa, formando cidadãos autônomos, com consciência crítica e solidária que constitui base do desenvolvimento pessoal e comunitário. Para atingir os fins de sua educação, além de ter como meio uma pedagogia apropriada, conta também com outo

\footnotetext{
${ }^{1}$ As Escolas Famílias Agrícolas - EFAs são instituições de ensino filantrópicas vinculadas ao MEPES e ofertam os anos finais do Ensino Fundamental e/ou Ensino Médio.

2 O MEPES - Movimento de Educação Promocional do Espírito Santo é uma Instituição Filantrópica, fundada em 1968, pelo Pe. Humberto Pietrogrande, cuja sede está localizada em Anchieta-ES, promove e desenvolve a cultura através da Ação Comunitária em uma ampla atividade relacionada com os interesses da agricultura e principalmente no que concerne à elevação social do agricultor. O MEPES interage com diversas instituições públicas e privadas e também Internacionalmente, mantendo convênios de cooperação técnica e financeira. No caso específico das EFA's, o Governo do Estado do Espírito Santo financia a contratação de profissionais para atuar nessas escolas e, em alguns casos, os Municípios atuam na manutenção do funcionamento do espaço e as famílias, que recebem os serviços educacionais das EFA's, contribuem com um valor financeiro para o estudo dos filhos.
} 
princípio muito importante que é a responsabilidade e condução do CEFFA ${ }^{3}$ pelas Famílias [...]. (ROCHA, 2007, p. 6-7).

Esta pedagogia articula diversos elementos pedagógicos num movimento de teoria e prática, envolvendo toda realidade concreta dos sujeitos do campo.

$\mathrm{Na}$ década de 80, juntamente com as ocupações de terra no Município de São Mateus e demais municípios do norte do Estado, surgem as escolas de assentamento.

Nesse sentido, Baldotto (2011) destaca que a luta do Movimento dos Trabalhadores Rurais Sem Terra - MST incluiu as mudanças gerais na sociedade e a educação foi concebida como uma porta para consolidação dessas mudanças:

A preocupação com a educação nos acampamentos e assentamentos surge no processo de luta pela terra, com o MST. A busca era por uma educação que fosse diferente daquela que existia naquele período. Segundo o relato da educadora Maria Zelinda Gusson ${ }^{4}$ (2010), [...] a pergunta todo dia no quadro era: Que tipo de educação eu quero para o meu filho? Então quer dizer que ela iniciou antes de iniciar o assentamento, antes de iniciar o acampamento. Por que quando a gente ia, agora menos, mas quando ia para o acampamento, já ia com o professor junto, já continuava a aula lá. Podia ser onde for, eu mesmo já trabalhei debaixo do pé de manga (BALDOTTO, 2011, p. 49).

A partir da década de 1990, alguns municípios do Norte do Estado do Espírito Santo, iniciaram a implementação de escolas com trabalho pedagógico similar ao das Escolas Famílias Agrícolas, essas escolas vinculadas à rede pública municipal foram denominadas de Escolas Comunitárias Rurais Municipais - ECORM ou Escola Municipal Comunitária Rural - EMCOR. Os Municípios que, gradativamente, implementaram essas escolas foram Jaguaré, Barra de São Francisco, Mantenópolis, Ecoporanga, Nova Venécia, Rio Bananal e Colatina.

\footnotetext{
${ }^{3}$ CEFFA - Centros de Formação por Alternância: todas as unidades escolares que trabalham com a Pedagogia da Alternância são consideradas CEFFAs.

${ }^{4}$ Maria Zelinda Gusson, educadora durante 20 anos em escolas do campo, acompanhou as primeiras escolas de acampamentos/ assentamentos no norte do Estado e atuou 23 anos no Setor Estadual de Educação do MST. Concedeu uma entrevista por meio do diálogo da História Oral Temática em 2010, para a pesquisa intitulada "Trabalhadores em Movimento: Trajetória do MST e a Educação No/Do Campo no Norte do Estado do Espírito Santo", concluída em 2011.
} 
No Município de São Mateus, o diálogo de expansão dessa proposta pedagógica pela via pública municipal inicia no ano de 2001, o que envolveu diversas lideranças da região, com a consequente estruturação da Comissão Municipal de Educação do Campo da Região de Nestor Gomes. Essa Comissão foi formada por representantes da EFA Km 41, Movimento dos Trabalhadores Rurais Sem Terra - MST, Movimento dos Pequenos Agricultores - MPA, lideranças comunitárias e educadores da região.

Em 2009, foi encaminhado ao Conselho Municipal de Educação de São Mateus, a Proposta Pedagógica e o Regimento das Escolas em Alternância de São Mateus para análise e emissão de parecer quanto ao funcionamento dessas escolas. Nesse contexto, o Parecer CME/SM no 09/2009, "Visando a regularização do funcionamento das Escolas Comunitárias Rurais Municipais de São Mateus" foi aprovado em 15 de dezembro de 2009, contemplou a importância desse ensino para os estudantes do campo: A partir dos estudos, visitas e da análise das legislações em
vigor que tratam do assunto ora em referência, esta Comissão
Especial conclui que a Rede Municipal de Ensino de São Mateus
deve assegurar ao educando residente no campo a
oportunidade de receber um ensino voltado para sua realidade
com garantia de qualidade. Porém, destacamos pontos a serem
considerados:

Neste primeiro momento de implantação das Escolas Comunitárias Rurais os professores sejam selecionados através de um processo com os efetivos na Rede Municipal, com critérios visando a identificação com a educação do campo e caso a carência não seja suprida que se realize processo seletivo para contratação temporária específica para essas escolas;

Que sejam incluídas vagas para contratação de professor, específico para as Escolas Comunitárias, no próximo concurso público a ser oferecido pelo Município; [...]

Que o município ofereça alimentação escolar, de qualidade e adequada, uma vez que se trata de educandos que serão atendidos em tempo integral. [...] (CONSELHO MUNICIPAL DE EDUCAÇÃO DE SÃO MATEUS, 2009, p. 5).

Este Parecer representou um "sim" para a criação e implementação das Escolas com Pedagogia da Alternância no Município, com denominação de Escolas Comunitárias Rurais Municipais - ECORM e no caso das escolas em 
território de Assentamento, o reconhecimento da Pedagogia do Movimento Sem Terra juntamente com a Pedagogia da Alternância.

Com toda essa mobilização foi possível alcançar uma grande conquista em 2010, com a criação da primeira escola em alternância pela rede municipal de São Mateus, atendendo a 70 estudantes dos anos finais do Ensino Fundamental, na região de Córrego Seco e na sequência, foi autorizada a implementação da Pedagogia da Alternância na EMEIEF ${ }^{5}$ Assentamento Zumbi dos Palmares para atender a 200 estudantes da Educação Infantil e Ensino Fundamental (anos iniciais e finais).

Em 2011, foi aprovado pelo Conselho Municipal de Educação de São Mateus o Parecer n 003/2011, que emite "Análise e parecer sobre a implantação da disciplina de Agricultura nas Escolas do Campo de São Mateus/ES":

No tocante às especificidades da Educação do Campo, [...] especialmente no que diz respeito aos conteúdos curriculares e metodologias apropriadas às reais necessidades e interesses dos alunos do campo, organização escolar própria, incluindo adequação do calendário escolar às fases do ciclo agrícola e às condições climáticas e adequação à natureza do trabalho camponês. (CONSELHO MUNICIPAL DE EDUCAÇÃO DE SÃO MATEUS/ES, Parecer $n^{\circ}$ 003/2011, de 04/11/2011).

Na construção de uma proposta de Educação do Campo no Município de São Mateus, foram consideradas todas as diretrizes do movimento da Educação do Campo, e a inserção da agricultura como disciplina nas escolas do campo teve como objetivo provocar as questões apontadas por Caldart (2015, p. 210), na relação agricultura e natureza:

A lógica da agricultura camponesa supõe o aproveitamento
crítico dos saberes e experiências dos antepassados e
apropriação ou produção de conhecimentos científicos
necessários aos desafios atuais dessa lógica de agricultura,
sobre a natureza, sobre as relações sociais, sobre as conexões
que compõem o processo de produção agrícola. E, sobretudo,
implica na reapropriação pelos camponeses da capacidade de
interpretar a relação agricultura e natureza. A matriz científica e
tecnológica da agroecologia torna a exigência de conhecimentos
científicos sobre a natureza, sobre a produção, ainda mais
rigorosa.

${ }^{5}$ EMEIEF - Escola Municipal de Educação Infantil e Ensino Fundamental. 
Outra conquista no ano de 2011, foi a criação da Gestão da Educação do Campo na estrutura da Secretaria Municipal de Educação de São Mateus, para acompanhamento às escolas do campo. Importante destacar que esse espaço dentro da Secretaria de Educação foi uma conquista por meio de diálogos com os movimentos sociais e lideranças comunitárias da região, no entanto essa ação não foi normatizada institucionalmente no organograma da Secretaria.

$\mathrm{Na}$ sequência, em 2011, aconteceu a estruturação do Comitê de Educação do Campo no Município de São Mateus, com representações dos diversos movimentos sociais, entidades civis e o poder público. A organização desse grupo representou a formalização das discussões na região, por ser um espaço permanente de articulação, deliberação e construção coletiva da Educação do Campo.

Nessa trajetória, em 2012, foi construído e implementado nas 40 Escolas Multisseriadas do Município, o PLAFEC/SM - Plano de Fortalecimento da Educação do Campo do Município de São Mateus: uma ação educativa contextualizada e integrada. Esse documento direciona todo o trabalho pedagógico com os estudantes da Educação Infantil e anos iniciais do ensino fundamental nas Escolas Multisseriadas e Escolas Comunitárias Rurais.

Em 2013, por iniciativa da comunidade, junto ao poder público municipal, foi implementada mais uma escola com pedagogia da alternância, numa região de pescadores e agricultura familiar, a ECORM Maria Francisca Nunes Coutinho, localizada na região do Nativo em Barra Nova.

Ressaltamos que tivemos momentos de conquistas e momentos de resistência pelo movimento da Educação do Campo no Município de São Mateus.

Nesse sentido, destacamos a ocupação ocorrida no prédio da Prefeitura de São Mateus, no dia 22 de fevereiro de 2016, que envolveu representantes do MST, MPA, Quilombolas, Educadores do Campo, Estudantes, Pais e representantes do Comitê Municipal de Educação do Campo de São Mateus. Essa ação foi motivada pelo início do calendário letivo no dia 15 de fevereiro de 2016, com a ausência de professores e transporte escolar nas escolas do campo. 
Durante a ocupação, aconteceram atos, palavras de ordens pelo direito a educação nas escolas do campo, nesse dia a aula aconteceu na rua. A ocupação da prefeitura encerrou no final do dia, após assinatura de uma nota de comprometimento pelos representantes da Prefeitura de São Mateus:

Aos 22 dias de fevereiro de 2016, a Superintendente de Controle Governamental, Dra. [sic] Sara Mendonça Santos Costa, a Coordenadora Geral, Dra. [sic] Juciene Lopes Thompson, o Secretário de Administração, Dr. [sic] Felipe Kohls e o Secretário de Finanças, Amauri Pinto Marinho, comprometeram-se perante o MPA, o Comitê Municipal de Educação do Campo, o MST, UMES e Associação de Moradores, Pais e Professores Municipais que até quarta-feira próxima, dia 24/02/2016:

1 - Serão encaminhadas às Escolas, profissionais para atender a demanda de professores, ASG's, pedagogos e coordenadores, em especial das escolas Zumbi dos Palmares, Nativo de Barra Nova, ECORM Córrego Seco e 42 Escolas Multisseriadas (pedagogos itinerantes);

2 - O edital de chamamento público da merenda escolar será revisto pela Secretaria Municipal de educação, juntamente com uma comissão eleita pelos solicitantes, comprometendo-se o Município, desde já, se for o caso, a adequar o edital à realidade da agricultura familiar local;

Obs.: Apesar do comprometimento, os solicitantes ficaram responsáveis em elaborar documento apontando os pontos do edital que julgarem inadequados para que o Município reveja.

3 - O transporte escolar funcionará de forma regular. Comprometeu-se, ainda, a verificar a possibilidade de realização de contrato visando atender à demanda dos alunos fazerem viagens e passeios extracurriculares mais de cunho educativo.

4 - [...] manutenção, cascalhamento (onde houver necessidade) e revitalização das estradas utilizadas pelos ônibus escolares que transitam em Santa Maria, Zumbi dos Palmares, Nova Verona, Córrego seco, Córrego do Aterro, Nativo, Antonio Lima, 27 de Outubro, Palmeira, Vale da Vitória e Pio $10^{\circ}$. OBS.: Em especial, no Córrego do Aterro, será necessária abertura de estrada; [...] (SÃO MATEUS/ES, 2016, p. 1).

Nesse contexto das memórias da caminhada da Educação do Campo no Município de São Mateus, é importante destacar que os pedagogos e diretores que acompanhavam as Escolas Multisseriadas atuavam com sede na Secretaria de Educação de São Mateus. No entanto, a partir da avaliação das comunidades juntamente ao Comitê municipal de Educação de São Mateus, esse cenário foi 
sofrendo mudanças para melhor atender as comunidades. Em 2013, os pedagogos passaram a atuar nas Escolas Multisseriadas, e em 2017, os diretores também foram localizados nas regiões com atuação em itinerância para acompanhamento a essas escolas.

Esse movimento foi muito importante e está possibilitando um trabalho pedagógico juntamente com os educadores, centralizado no estudante e nas famílias, de maneira a considerar suas especificidades e a realidade concreta das/nas comunidades.

\section{O Projeto Político Pedagógico - PPP das Escolas do Campo}

A abordagem das dimensões do processo pedagógico nos coloca na perspectiva do "fazer pedagógico", uma vez que "este" vem carregado de intencionalidades e possibilidades, também expressas no Projeto Político Pedagógico da Escola. As dimensões são os eixos que perpassam as intencionalidades de nossa ação formativa no cotidiano, por isso, dizem respeito a todos os elementos pedagógicos desenvolvidos pelos educadores com os estudantes.

Não se pode pensar Educação do Campo, sem considerar o educador que irá desenvolver os elementos pedagógicos da proposta educativa do campo. Esse educador deve refletir de forma crítica e constantemente sua prática pedagógica, estar comprometido com os ideais pedagógicos humanizadores, se comprometer com o ensino-aprendizagem significativo e se posicionar por uma educação pública e de qualidade.

Para tanto, é essencial uma formação continuada e específica voltada para essas dimensões e a realidade do Campo. Dessa forma, Caldart (2004, p. 35-36) frisa a importância dessa formação:

Construir a Educação do Campo significa formar educadores e educadoras do campo para atuação em diferentes espaços educativos. E se defendemos uma formação específica é porque entendemos que boa parte deste ideário que estamos construindo é algo novo em nossa própria cultura. Há uma nova identidade de educador que precisa ser cultivada, ao mesmo tempo em que há toda uma tradição pedagógica e um acúmulo de conhecimentos sobre a arte de educar que precisa ser 
recuperada e trabalhada desde esta intencionalidade educativa da Educação do Campo.

O Projeto Político Pedagógico - PPP é um dos mais importantes documentos da escola, nele está contido todo o trabalho pedagógico no âmbito da concepção, realização e da avaliação do projeto educativo. Precisa garantir a intencionalidade política do trabalho pedagógico e contribuir na construção de um espaço de reflexão que possibilite compreender a ideologia que reside nos discursos e práticas pedagógicas.

É necessário reconhecer que educar é um ato político, as escolas estão situadas em uma sociedade, que historicamente, é dividida em classes, cujo modo de produção é capitalista, daí a importância de se pensar no papel político e pedagógico da escola, sua intencionalidade e um compromisso social.

Destarte, a Lei № 1.798\2020, aprovada em 20 de fevereiro de 2020, "Estabelece e fixa normas para a oferta da Educação do Campo na Rede Municipal de Ensino de São Mateus/ES e dá outras providências", nos aponta em seu Art. $3^{\circ}$, Parágrafo Único, que:

As unidades de ensino do campo e as turmas anexas deverão elaborar seu Projeto Político Pedagógico (PPP), na forma estabelecida pelas Diretrizes Operacionais para a Educação Básica nas Escolas do Campo, pelas Diretrizes Curriculares Nacionais para a Educação Escolar Quilombola e legislação municipal que rege a Educação do Campo. (SÃO MATEUS, 2020, p. 02)

Nesse sentido, e considerando que toda ação pedagógica e formativa vem carregada de intencionalidades e possibilidades, ressaltamos que Projeto Político Pedagógico das escolas do campo, um documento a ser construído coletivamente pela comunidade escolar, precisa caracterizar a identidade e valorização dos povos do campo e apontar caminhos com vistas à sociedade que queremos construir.

Diante disso, a Lei № $1.798 \backslash 2020$ estabelece ainda que:

Art. 29. O Projeto Político Pedagógico - PPP da escola do campo ou escola que recebe estudantes oriundos dessas comunidades deverá: 
I. contemplar os princípios da Educação do Campo constantes nas Diretrizes Operacionais da Educação do Campo e Diretrizes Curriculares Nacionais para a Educação Escolar Quilombola;

II. atender a realidade histórica, regional, política, sociocultural, econômica e educacional das comunidades do campo;

III. ser construído de forma coletiva mediante o envolvimento e participação de toda a comunidade local;

IV. ser construído a partir do diagnóstico da realidade camponesa de seus estudantes; [...] (SÃO MATEUS, 2020, p. 09-10)

A referida lei municipal, ainda estabelece como deverá ser construído o PPP das unidades de ensino do campo do Município de São Mateus e aponta ainda para o papel que terão as comunidades campesinas nessa construção coletiva, conforme trecho abaixo:

Art. 30. Os Projetos Políticos Pedagógicos - PPPs das unidades de ensino do campo serão construídos juntamente com as comunidades camponesas e estas terão a prerrogativa de decidir o tipo de ensino apropriado aos seus modos de vida.

[...] $\S 2^{\circ}$. Cabe à Secretaria Municipal de Educação promover consulta prévia e informada sobre o tipo e modalidade de educação que atenda às diversas comunidades do campo, realizando diagnóstico das demandas relativas a cada realidade camponesa, por meio de ações colaborativas com as comunidades (SÃO MATEUS, 2020, p. 10).

As Escolas Multisseriadas do campo no Município de São Mateus|ES, que atendem estudantes da Educação Infantil ao $5^{\circ}$ ano do Ensino Fundamental, terão seu PPP, conforme o Parágrafo Único da Lei supracitada, consolidado por meio do "Plano de Fortalecimento da Educação do Campo de São Mateus PLAFEC/SM: uma ação educativa contextualizada e integrada”.

O PLAFEC/SM, refere-se a um documento estruturado e implementado no ano de 2012, pela Secretaria Municipal de Educação de São Mateus, juntamente aos educadores das Escolas Multisseriadas da rede, e surge:

[...] surge da necessidade de implantar e implementar um Plano de Ensino que atenda aos anseios campesinos, valorizando a identidade e cultura desses povos. Assim, o projeto estruturado para todas as Escolas Multisseriadas do campo, tem como principal objetivo a inserção das realidades campesinas na vivência escolar, através da realidade dos estudantes, integrando teoria e prática na estruturação do conhecimento do 
processo ensino-aprendizagem (SECRETARIA MUNICIPAL DE EDUCAÇÃO DE SÃO MATEUS, 2012, p. 42).

Os elementos pedagógicos que englobam as propostas pedagógicas das escolas do campo no Município de São Mateus, são: Plano de Estudo (PE), Conteúdos/Atividades Vivenciais (visitas, oficinas, palestras e viagens de estudo), Atividade de Retorno (AR), Caderno de Acompanhamento (CA) ou Caderno de Reflexão, Estadia Letiva, Pasta/Caderno da Realidade, Avaliação de Habilidade e Convivência (AHC), Auto-organização e Mística.

O Plano de Estudo (PE) é a base de todo processo da proposta da Educação do Campo, esse elemento é construído pelos estudantes, juntamente com os educadores e desenvolvido/respondido junto à família. Esse movimento dá sentido ao currículo de uma escola do campo, pois tem a função de pesquisar a realidade concreta, com foco no tema gerador, junto à família ou comunidade do estudante, atendendo ao que a legislação aponta como protagonismo estudantil.

O PLAFEC/SM, ao conceituar o Plano de Estudo, salienta que esse elemento pedagógico:

[...] tem a função de fazer a investigação da realidade concreta, no nível do conhecimento empírico e depois passado pelas fases de Colocação em Comum e síntese, as quais fornecem as novas hipóteses, que por sua vez são exploradas pelas bases tecnológicas, aprofundadas através das disciplinas e outras atividades (visitas e viagens de estudo, oficinas, palestras, depoimentos e outros). Dessa forma é possível tomar consciência da realidade e ter uma nova atitude em relação aos fenômenos da vida (SECRETARIA MUNICIPAL DE EDUCAÇÃO DE SÃO MATEUS, 2012, p. 26).

De acordo com o PLAFECISM (2012, p. 29) os Conteúdos\Atividades Vivenciais são:

[...] todas as expressões de conhecimentos extraídos da realidade vivencial dos estudantes. São elementos da realidade que o estudante percebeu com precisão, somados aos conhecimentos que ele já tem da realidade. No processo educativo, esses conhecimentos se relacionam com o científico transformando-se em conhecimento com sentido para a vida do estudante. 
Os Conteúdos ou Atividades Vivenciais são planejados a partir dos pontos de aprofundamentos vinculados ao tema de estudo de cada turma, que são motivados, estruturados e avaliados junto aos estudantes, devendo compor a Pasta da Realidade.

A Pasta da Realidade é o elemento em que o estudante organiza e arquiva a pesquisa e as atividades desenvolvidas a partir dos pontos pesquisados no meio familiar com vínculo no tema gerador. O PLAFEC/SM nos elucida ainda quanto ao nível pedagógico que a Pasta da Realidade representa:

Tomada de consciência e uma particular percepção da vida cotidiana do estudante.

Desenvolvimento da formação geral, porque retrata a história da família, da terra que trabalha, da comunidade e de outros aspectos que compõem a vida familiar.

O compromisso com a transformação da realidade vivida pelo estudante, através do processo de tomada de consciência e análise sistematizada dessa realidade (SECRETARIA MUNICIPAL DE EDUCAÇÃO DE SÃO MATEUS, 2012, p. 30).

É importante destacar que em 2012, este elemento recebia o nome de caderno da realidade, no entanto todo arquivo acontecia em uma pasta catálogo por ser um objeto de manuseio prático para os estudantes. Os estudantes da Educação Infantil e dos anos iniciais do Ensino Fundamental, somente identificavam este elemento pedagógico quando perguntávamos pela Pasta da Realidade. Daí a necessidade de utilizarmos atualmente a expressão pasta da realidade, por ser um elemento concreto na vivência escolar dos estudantes.

A Atividade de Retorno possibilita ao estudante refletir sobre o quanto se aproximou de soluções para os problemas anteriormente levantados durante 0 tema estudado e que foram apropriados pelo currículo da escola por meio da pesquisa realizada junto a família e/ou comunidade. É chegado o momento do estudante, com total protagonismo, retornar para a família e comunidade, o conhecimento científico que adquiriu após aprofundar sobre determinado tema da realidade.

O PLAFEC, contextualiza a tarefa do estudante na organização da Atividade de Retorno: 
Agora ele traduz oralmente, escrito, ilustrado ou através de uma ação prática na sua família/comunidade a compreensão que teve de todo o processo de ensino aprendizagem durante o período de estudo do Plano de Estudo. Expressa sua nova maneira de ver a sua vivência. Este é o momento da avaliação que traduz o crescimento do estudante, que expressa como se apropriou do conteúdo, como resolveu as questões propostas, como reconstituiu seu processo de concepção da realidade, sempre considerando o ciclo de vida que se encontra. (SECRETARIA MUNICIPAL DE EDUCAÇÃO DE SÃO MATEUS, 2012, p. 30).

O Caderno de Acompanhamento ou Caderno de Reflexão é o elemento pedagógico com a função de orientar diretamente o estudante no tempo da Estadia Letiva (meio familiar ou comunitário) contempla o planejamento do estudante e o diálogo entre a família e escola.

De acordo com o PLAFEC (2012, p. 29), o Caderno de Acompanhamento "Permite ao estudante planejar e registrar suas tarefas de vivência e estudo. Favorece a família na sua função educativa do acompanhamento na vida escolar dos estudantes em suas potencialidades e necessidades".

A Lei Municipal No 1.798\2020, em seu Art. 42, inciso VI, destaca que a Estadia Letiva é o "momento em que o estudante executa as atividades orientadas pelo educador vinculadas ao do Tema Gerador, no contexto do TRABALHO-VIVÊNCIA-ESTUDO e preenche o Caderno de Acompanhamento ou Caderno de Reflexão" (SÃO MATEUS, 2020, p. 10). Essa mesma lei estabelece os tipos de atividades a serem realizadas nas Estadias Letivas:

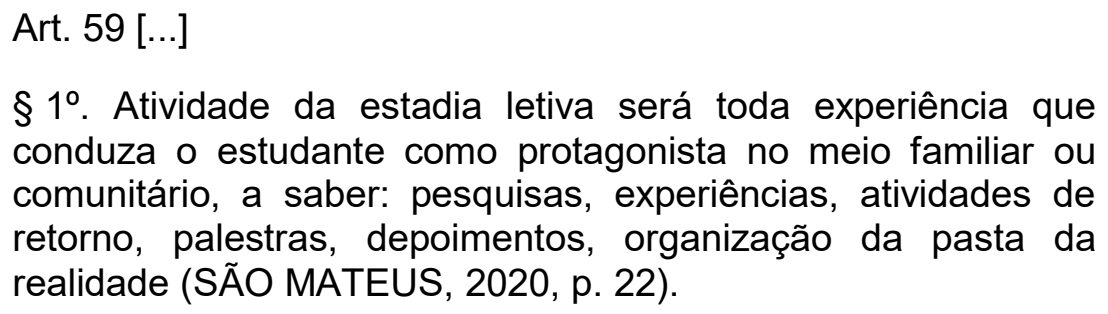
conduza o estudante como protagonista no meio familiar ou comunitário, a saber: pesquisas, experiências, atividades de retorno, palestras, depoimentos, organização da pasta da realidade (SÃO MATEUS, 2020, p. 22).

A lei municipal supracitada, descreve em seu Art. 42, inciso VIII, a Avaliação de Habilidade e Convivência (AHC) como o "momento de auto avaliação dos estudantes nas temáticas TRABALHO, VIVÊNCIA e ESTUDO, que deverá possuir roteiro de planejamento com relatórios que devem compor a Pasta da Realidade" (SÃO MATEUS, 2020, p. 16). Esse elemento pedagógico 
também possibilita que os estudantes avaliem uns aos outros e sejam avaliados pelas suas famílias.

A Auto-organização, outro elemento presente na proposta pedagógica, favorece a autonomia, a cooperação, a solidariedade e a capacidade de organização dos estudantes, além de possibilitar a integração e a vivência em grupo.

Dessa forma, as propostas pedagógicas consideram a realidade de cada escola do campo, contemplando diretrizes gerais de envolvimento e organicidade dos estudantes no cotidiano escolar.

A Mística, uma dimensão primordial do "fazer pedagógico" nas escolas do campo,

[...] expressa-se através da poesia, do teatro, da expressão corporal, de palavras de ordem, da música, do canto, dos símbolos, das ferramentas de trabalho, do resgate da memória e se torna um momento de celebração que envolve os diversos sujeitos em um mesmo objetivo do coletivo" (SÃO MATEUS, 2020, p. 16).

Esse elemento pedagógico mobiliza todas as demais atividades desenvolvidas na escola por envolver todos na defesa de uma causa e projeto, possibilita a defesa ou denúncia de determinado tema e sempre com muito significado e conteúdo em suas abordagens e dimensões.

Considerando o histórico apresentado acerca da efetivação da modalidade Educação do Campo no Brasil e em nosso Município, e considerando ainda, as especificidades Educacionais, Políticas e Sociais que são próprias das comunidades e estudantes campesinos, entendemos a Formação Continuada como uma ação imprescindível para a garantia de um processo de ensino-aprendizagem, no campo, que garanta minimamente o que está estabelecido legalmente.

Diante do exposto, a formação continuada da equipe escolar faz-se necessário para garantir a efetivação da proposta pedagógica e seus diversos elementos pedagógicos:

Por isso defendemos com tanta insistência a necessidade de políticas e projetos de formação das educadoras e dos educadores do campo. Também, porque sabemos que boa parte 
deste ideário que estamos construindo é algo novo em nossa própria cultura, e que há uma nova identidade de educador que pode ser cultivada a partir deste movimento por uma educação do campo (CALDART, 2011. p. 158, Grifos do autor).

Nesse sentido, em parceria com o Centro Universitário Norte do Espirito Santo - CEUNES, um polo de extensão da UFES no Município de São Mateus foi proposta ao longo do ano letivo de 2019, uma formação continuada em serviço para os profissionais (Educadores, Pedagogos e Diretores) lotados nas escolas do campo. Uma formação com vistas a retomar os diálogos acerca da proposta e finalidade da Educação do Campo, além de abordar na prática e através da prática, todos os elementos que compõem essa proposta pedagógica.

\section{Formação Continuada de Educadores/as: Dimensões Pedagógicas das} Práticas Educativas nas Escolas do Campo no Município de São Mateus/ES

O principal compromisso das universidades públicas é para com o saber sistematizado, todavia, é indiscutível o seu compromisso com os problemas e desafios concretos colocados pela sociedade. Embora as universidades não tenham o papel de dar um retorno imediato à sociedade, cabe a elas formar profissionais críticos, com competência científica, técnica e social, para que tenham capacidade de enfrentar os desafios postos pela realidade.

Nesse sentido, é importante que as universidades desenvolvam projetos integrados de pesquisa e educação que atendam as áreas de maior relevância social e econômica, tais como agroecologia, saúde, produção de alimentos, educação básica, Educação do Campo, dentre outros. Para tanto, as universidades devem estar inseridas nos diversos setores da sociedade, não somente para identificar e ofertar especialização e complementação produtiva e tecnológica, mas também, para promover uma reflexão intrínseca dos problemas de determinada região.

Dessa forma, levando em consideração a necessidade da formação continuada para os educadores e educadoras do campo do Município de São Mateus/ ES, o Projeto de Extensão intitulado "Formação Continuada de Educadores/as: Dimensões Pedagógicas das Práticas Educativas nas Escolas do Campo no Município de São Mateus/ES", aconteceu no decorrer do ano de 
2019, com a coordenação do Professor Adelar João Pizetta, vinculado ao Centro de Educação e Ciências Humanas (DECH/CEUNES/UFES), em parceria com a Secretaria Municipal de Educação de São Mateus/ES, por meio do Setor de Educação do Campo.

Esse projeto envolveu os educadores, pedagogos e diretores das Escolas com Pedagogia da Alternância e das Escolas Multisseriadas, com organização dos estudos em momentos coletivos e momentos internos nas escolas.

Assim, os encontros aconteceram nas diversas regiões de localização das escolas do campo no Município de São Mateus e no espaço da Secretaria Municipal de Educação. A formação baseou-se em grandes temáticas vinculadas a proposta pedagógica das escolas do campo, permitindo que os participantes vivenciassem o contexto teórico articulado à prática pedagógica desenvolvida em sala de aula.

O Projeto de Extensão foi estruturado em dois grupos de cursistas na formação, sendo um grupo de gestores envolvendo 34 (trinta e quatro) pedagogos e diretores, com 180 horas de formação, e outro grupo com 132 (cento e trinta e dois) educadores, com 100 horas de formação.

O curso foi organizado em três módulos de um trimestre (três meses) cada, contemplando temáticas de estudo sobre a identidade camponesa, o legado pedagógico construído a partir do Movimento Nacional da Educação do Campo e os conteúdos com associação da teoria e prática no contexto das propostas pedagógicas desenvolvidas nas escolas do campo vinculadas a Rede Municipal de São Mateus.

No decorrer da formação, o estudo foi organizado em tempo formação TF, tempo escolar - TE e tempo comunidade - TC, que possibilitou um entrelaçamento entre o estudo, a prática escolar e a vida da/na comunidade em que a escola se encontra inserida. Nesses tempos formativos, as etapas envolveram os educadores e equipe gestora das unidades escolares, com articulação e vivência de ações envolvendo os estudantes e famílias.

O Tempo de Formação integrou o cursista nas atividades de estudo, atividades vivenciadas no cotidiano escolar, seminários e demais atividades que possibilitaram reflexão da prática pedagógica nas Escolas do Campo. Por outro 
lado, o Tempo Escolar possibilitou ao cursista a sistematização e produção textual do caderno pedagógico com a organização e arquivo de todos os elementos pedagógicos desenvolvidos com os estudantes durante o ano letivo de 2019. O Tempo Comunidade integrou os demais tempos da formação como uma intervenção organizada, a partir do trabalho pedagógico no meio comunitário em que a escola se encontra inserida.

Esse movimento formativo possibilitou rememorar todo o acúmulo histórico que o movimento de construção da proposta pedagógica da Educação do Campo possui no Município de São Mateus e, principalmente, fortalecer a identidade dos sujeitos que vivem, lutam e/ou lutaram em defesa da escola em território campesino.

Com o intuito de fortalecer a relação Universidade-Comunidade, e contribuir na formação de profissionais que atuam na Educação Básica no/do Campo, o curso ainda teve como objetivos: possibilitar aos participantes o estudo, discussão e reflexão da prática pedagógica, com o aprimoramento das estratégias pedagógicas; vivenciar atividades diretamente ligadas aos elementos pedagógicos da proposta educativa das/nas Escolas Campesinas de São Mateus; possibilitar a apreensão da teoria e prática por meio do referencial da Educação do Campo; desenvolver a sistematização e a produção textual das práticas pedagógicas no Tempo Escolar e no Tempo Comunidade.

Dessa forma a cursista e educadora da EPM Vaversa, Sueli Moreira Lima Soares (2019), destaca que:

[...] Gostei muito da metodologia adotada nos encontros em 2019. Éramos organizados em grupos para planejarmos os questionários dos temas de estudo e os enfoques para o trimestre seguinte. Esses momentos nos davam a oportunidade de trocar ideias e experiências com os colegas de outras escolas e com os professores de área específica da nossa unidade de ensino, o que também facilitava a vida de todos os envolvidos, pois com nossas correrias por trabalhar em dois turnos, já saíamos desses encontros com parte de nossas atividades adiantadas ou prontas.

Considero essas formações importantes, pois possibilita uma reflexão que nós enquanto educadores precisamos cotidianamente fazer: pensar e repensar nossas ações. Esse conjunto de aprendizado e reflexão é um estímulo para que eu 
melhore cada vez mais o meu trabalho (SECRETARIA DE EDUCAÇÃO DE SÃO MATEUS/ES, 20196).

Ao longo do processo formativo, os cursistas realizaram três exposições, contemplando os elementos pedagógicos da Educação do Campo desenvolvidos em cada unidade escolar pelos educadores e estudantes:

I Exposição - Tema: "Os elementos pedagógicos da Educação do Campo", período de 27/05 à 31/05/2019;

II Exposição - Tema: "Compartilhando Saberes", período de 16/09 à 23/09/2019;

III Exposição - Tema: "Agricultura e Pedagogia - as raízes da Educação do Campo", período de 25/11 à 29/11/2019.

As exposições aconteceram no espaço da Secretaria Municipal de Educação de São Mateus/ES, e tiveram o objetivo de socializar as atividades pedagógicas vinculadas às propostas pedagógicas das escolas do campo realizadas pelos estudantes e equipes pedagógicas das unidades escolares (educadores, pedagogos e diretores). Essa ação mobilizou o espaço da Secretaria Municipal de Educação, com a visitação das escolas urbanas, equipes da própria Secretaria e estudantes do Ensino Superior.

O Setor de Educação do Campo usufruiu da presença dos materiais pedagógicos da proposta nas exposições para avaliar a práxis dos educadores, pedagogos e diretores, com posterior devolutiva e contribuição às unidades escolares.

A diretora de escolas do campo, Monica Soares (2020), destaca em seu depoimento que:

Os encontros formativos que aconteceram em 2019 na nossa rede municipal de educação em parceria com o CEUNES, foram momentos marcantes e muito ricos em nossa vida como profissionais da Educação do Campo.

Tivemos a oportunidade de realizar momentos em cada região, cada escola, e também momentos com todo o coletivo da Educação do Campo. Foram oportunidades de planejar, construir, avaliar... Possibilitando o fortalecimento dos nossos instrumentos e consequentemente da nossa proposta

\footnotetext{
${ }^{6}$ Arquivo da Formação Continuada de Educadores/as: Dimensões Pedagógicas das Práticas Educativas nas Escolas do Campo no Município de São Mateus/ES, 2019.
} 
pedagógica. E como gestora, tive a tarefa de conduzir alguns momentos de nossas formações, experiência que somente me enriqueceu como educadora, mas também como militante da Educação do Campo.

Avalio que o caminho ainda é longo, muito já se conquistou, porém a nossa luta é contínua para a manutenção e melhoria das nossas escolas do campo, e nesse contexto, as formações são essenciais para cada dia melhorarmos nossa prática (SECRETARIA DE EDUCAÇÃO DE SÃO MATEUS/ES, 20197).

Nessa jornada de estudos, organizou-se o II Encontro Municipal das Escolas do Campo de São Mateus, com o Tema: "Práticas Pedagógicas em Escolas do Campo: um diálogo em Construção", no dia 23 de agosto de 2019, no CEFOCAF - Centro de Formação e Capacitação da Agricultura Familiar, localizado atrás do CEUNES. O II Encontro possibilitou a socialização das diversas práticas desenvolvidas nas escolas do campo, com abrangência na Educação Infantil, Ensino Fundamental I e II, Educação de Jovens e Adultos EJA. O seminário envolveu as diversas lideranças e instituições que discutem a Educação do Campo na região Norte e Extremo Norte do Estado do Espírito Santo.

Com a avaliação dessa formação continuada, foi possível perceber que a realização do Projeto de Extensão com a participação da equipe gestora (diretores e pedagogos) e educadores das escolas do campo teve um efeito multiplicador importante, pois, em seu cotidiano escolar puderam desenvolver estudos sobre a prática realizada e redimensioná-la no contexto da autonomia pedagógica, vinculada ao Projeto Político Pedagógico de cada escola do campo.

Destaca-se também o envolvimento de diversos professores da Universidade, professores das Escolas Famílias Agrícolas e profissionais da Secretaria Municipal de Educação de São Mateus - ES, que de forma voluntária, ministraram as aulas, orientando os estudos.

A partir da avaliação realizada com os cursistas, em dezembro de 2019, podemos destacar que: a) A organização do cronograma de atividades da formação permitiu que as equipes pautassem a discussão de elementos necessários à implementação da proposta, que se evidenciou na construção e

\footnotetext{
${ }^{7}$ Arquivo da Formação Continuada de Educadores/as: Dimensões Pedagógicas das Práticas Educativas nas Escolas do Campo no Município de São Mateus/ES, 2019.
} 
revisão das Propostas Político Pedagógicas pelas Escolas do Campo, proporcionando maior organicidade e articulação escola/comunidade, ainda que o tempo dedicado para essa ação fosse considerado curto pela maioria dos profissionais; b) Outro aspecto relevante foi que a realização dos encontros formativos nas regiões campesinas com estudos dirigidos, reuniu maior número de docentes e proporcionou a troca de experiências, o que permitiu maior compreensão do Plano de Estudo, tornando mais eficaz seu planejamento e desenvolvimento; c) A implementação do Caderno Pedagógico como forma de assegurar o registro do trabalho pedagógico realizado a partir do Tema Gerador nas unidades escolares do campo, apesar de, inicialmente, ter sofrido alguma resistência, se consolidou como um instrumento de sistematização e organização da práxis pedagógica.

Se por um lado, a formação veio consolidando a implementação da Proposta Pedagógica, por outro, nos faz refletir sobre a necessidade de projetar novas intervenções, no sentido de dar continuidade a formação, considerando que há uma grande rotatividade de docentes nas escolas campesinas de São Mateus.

Todo trabalho produzido e que serviu de base para análise e reflexão da nossa prática, apontaram a necessidade de maior direcionamento e planejamento dos elementos pedagógicos no cotidiano escolar com os estudantes e famílias.

\section{Considerações finais}

A presença da UFES para além do seu espaço físico enquanto coordenação do Curso de Extensão, proporcionou um envolvimento direto com a Educação Básica no Município de São Mateus - ES, contribuindo para o diálogo e fortalecimento do "fazer pedagógico" nas escolas do campo.

O Projeto de Extensão desenvolvido por meio da "Formação Continuada de Educadores/as: Dimensões Pedagógicas das Práticas Educativas nas Escolas do Campo no Município de São Mateus/ES” mobilizou o cotidiano pedagógico da escola com ações que permitiram a reflexão e reestruturação de práticas envolvendo estudantes, famílias e toda equipe escolar. 
Nesse sentido, a formação continuada redirecionou ações concretas de intervenção junto aos cursistas-educadores, visto que possibilitou um movimento contínuo de reflexão, planejamento e avaliação no contexto dialético de teoria e prática presente na proposta pedagógica das escolas. As intervenções aconteceram a partir das práticas e possibilitaram a reconstrução e construção

de novos "fazeres pedagógicos" a partir da realidade concreta de uma escola do campo e sua comunidade. Estamos concebendo um processo em constante construção, que vale parafrasear a cursista Monica, "tivemos muitas conquistas, no entanto a luta é contínua para a manutenção e melhoria das nossas escolas, e nesse contexto, as formações são essenciais para cada dia melhorarmos nossa prática".

Dessa forma, considerando a relevância do Projeto, do trabalho realizado, com adaptações e reorganização das temáticas, o Projeto foi renovado junto à UFES, dando continuidade a essa importante parceria.

\section{Referências}

ARROYO, Miguel Gonzales; CALDART, Roseli Salete; MOLINA, Monica Castagna (orgs). Por uma Educação do Campo. 5a. ed. Petropólis, RJ: Ed. Vozes, 2011.

BALDOTTO, Ozana Luzia Galvão. Trabalhadores em Movimento: Trajetória do MST e a Educação No/Do Campo no Norte do Estado do Espírito Santo. 2011. 131 f. Monografia (Ensino na Educação Básica) - Programa de PósGraduação Lato Sensu da UFES - Universidade Federal do Espírito Santo Centro Universitário Norte do Espírito Santo - Campus São Mateus.

CALDART, Roseli Salete. Elementos para a construção do Projeto Político e Pedagógico da Educação do Campo. In: MOLINA, Mônica Castagna; JESUS, Sonia Meire Santos Azevedo de (Orgs). Contribuições para a construção de um Projeto de Educação do Campo. Brasília, DF: Articulação Nacional por Uma Educação do Campo, 2004. Coleção Por Uma Educação do Campo, $n^{\circ} 5$, p. 13-49.

CALDART, Roseli Salete. In: CALDART, Roseli Salete; STEDILE, Miguel Enrique; DIANA, Daros (Orgs). Caminhos para a transformação da escola 2 - Agricultura camponesa, educação politécnica e escolas do campo. São Paulo: Expressão Popular, 2015.

CALDART, Roseli Salete. Por uma Educação do Campo: traços de uma identidade em construção. In: $\quad$ ARROYO, Miguel Gonzalez; $\quad$ CALDART, 
Roseli Salete; MOLINA, Mônica Castagna (Orgs.). Por Uma Educação do Campo. 5a . ed. Petropólis, RJ: Ed. Vozes, 2011. p. 147-158.

KOLLING, Edgar Jorge; NERY, Irmão; MOLINA, Mônica Castagna (Org.). Por uma educação básica do campo (Memória). Brasília: Universidade de Brasília, 1999 [?].

PIRES, Angela Maria, M. da M. Educação do campo como direito humano.

São Paulo: Cortez, 2012- (Coleção educação em direitos humanos; v. 4)

ROCHA, Isabel Xavier de Oliveira. Formação Integral nos CEFFAs Revista Formação por Alternância, Belo Horizonte, ano 3, dezembro 2007, n 5 , p. 05 18, 2007.

EDUCADORES DA REFORMA AGRÁRIA - II ENERA. ENCONTRO NACIONAL DE EDUCADORAS E EDUCADORES DA REFORMA AGRÁRIA, II ENERA, 2015, Luziânia - GO. MANIFESTO DAS EDUCADORAS E DOS EDUCADORES DA REFORMA AGRÁRIA AO POVO BRASILEIRO. LuZiânia: MST, 2015.

SECRETARIA MUNICIPAL DE EDUCAÇÃO DE SÃO MATEUS - ES. PLAFEC Plano de Fortalecimento da Educação do Campo. São Mateus, ES: [s.n.], 2012. 43 p.

CONSELHO MUNICIPAL DE EDUCAÇÃO DE SÃO MATEUS. Parecer $n^{\circ} .009$ de 15 de dezembro de 2009. Solicita parecer visando a regularização do funcionamento das Escolas Comunitárias Rurais do Município de São Mateus/ES, São Mateus, 15 dez. 2009. p. 06.

CONSELHO MUNICIPAL DE EDUCAC̄̃̃O DE SÃO MATEUS. Parecer $n^{\circ} .003$ de 04 de novembro de 2011. Análise e parecer sobre implantação da disciplina de agricultura nas escolas do campo de São Mateus/ES, São Mateus, 14 nov. 2011. p. 09.

SÃO MATEUS/ES. Prefeitura de São Mateus/ES. Nota de Comprometimento. São Mateus, 2016.

SÃO MATEUS/ES. Prefeitura Municipal de São Mateus. Lei № 1.79812020: Estabelece e fixa normas para a oferta da Educação do Campo na Rede Municipal de Ensino de São Mateus/ES e dá outras providências. São Mateus, 2020.

\section{Sobre os autores}

Ozana Luzia Galvão Baldotto

ozananv@yahoo.com.br

Mestre pelo Programa de Pós-Graduação em Ensino na Educação Básica (PPGEEB) Universidade Federal do Espírito Santo - UFES, São Mateus-ES, Brasil; Pedagoga na Rede Municipal de Ensino de São Mateus, na função de 
Gestora da Educação do Campo - Secretaria Municipal de Educação de São Mateus - Espírito Santo, Brasil.

\section{Adelar João Pizetta}

adelar.pizetta@ufes.br

Professor na Universidade Federal do Espírito Santo, Campus de São Mateus (CEUNES)

\section{Vitor Eduardo Mendes de Oliveira}

vitormendes2@hotmail.com

Especialista em Gestão Escolar Integradora e Psicopedagogia Institucional. Licenciado em Letras Português/ Inglês; Pedagogo e Professor de Inglês na Rede Municipal de Educação de São Mateus, atua na função de Gestor da Educação do Campo - Secretaria Municipal de Educação de São Mateus Espírito Santo, Brasil.

\section{Renata Cristina Araújo Gomes}

renatacris_araujo@hotmail.com

Mestre pelo Programa de Pós-Graduação em Ensino na Educação Básica (PPGEEB) Universidade Federal do Espírito Santo - UFES, São Mateus-ES, Brasil; Licenciada em Matemática, na função de Diretora Pedagógica Secretaria Municipal de Educação de São Mateus - Espírito Santo, Brasil.

\section{Fernando Vittorazzi Braz}

fernandovbraz@gmail.com

Especialista em Ciências Biológicas e Gestão Escolar; Licenciado em Ciências Biológicas; Professor de Ciências da Rede Municipal de Educação de São Mateus, com atuação na função de Gestor da Educação do Campo - Secretaria Municipal de Educação de São Mateus - Espírito Santo, Brasil.

\section{Eliete Rosa Fernandes}

elie.tefernandes@hotmail.com

Licenciada em Pedagogia - Habilitação em Magistério da Pré-Escola das Séries Iniciais do Ensino Fundamental (Projeto Educadoras e Educadores do Movimento dos Trabalhadores Rurais Sem Terra) Universidade Federal do Espírito Santo - UFES, São Mateus-ES, Brasil; Professora da Rede Municipal de Ensino de São Mateus, na função de Gestão da Educação do Campo Secretaria Municipal de Educação de São Mateus - Espírito Santo, Brasil. 